\title{
COST EFFECTIVE NATURAL ADSORBENTS FOR THE REMOVAL OF FLUORIDE: A GREEN APPROACH
}

\author{
Samiksha Tamrakar ${ }^{1, *}$, Rashmi Verma ${ }^{2}$, Santosh Kumar Sar ${ }^{3}$ \\ and Chanda Verma ${ }^{4}$ \\ ${ }^{1}$ Dept of Chemistry, Dr. C. V. Raman University, Bilaspur, 495113 Chhattisgarh, India** \\ ${ }^{2}$ Dept of Chemistry, Dr. C. V. Raman University, Bilaspur, 495113Chhattisgarh, India** \\ ${ }^{3}$ Dept of Applied Chemistry, Bhilai Institute of Technology, Durg, 491001, Chhattisgarh, India \\ ${ }^{4}$ Dept of Chemistry, St Thomas College, Bhilai, 496006, Chhattisgarh,India \\ *E-mail: samiksha.tamrakar3@gmail.com
}

\begin{abstract}
Access to safe drinking water is not only fundamental to human development and well being but is also recognized as a human right. The provision of safe potable water is considered critical and pivotal to the achievements of overall development, including adequate nutrition, education, gender equality and especially the eradication of poverty in developing countries. Fluoride is one of the water quality parameters of concern, the excess (beyond 1.5 $\mathrm{mg} / \mathrm{L}$, the World Health Organization (WHO) guideline value of which contaminates groundwater resources in many parts of the world, and renders it not potable for human consumption, due to the related adverse health effects. Therefore knowledge of its removal, using the best technique with optimum efficiency is needed. Taking the severity of the problem into consideration, the present paper aims to provide a retrospective approach to the use of effective low -cost adsorbents for the removal of fluoride from water. The defluoridation capacity of certain lowcost natural adsorbents like Citron peel, Karanj, Parijaat, Neem, Rice husk, and Tulsi was added in the list and discussed in detail. The effect of contact time, $\mathrm{pH}$ and adsorbent dose were investigated. The adsorption isotherm and kinetics were studied conducting Batch and Column experiment.
\end{abstract}

Keywords: Fluoride removal, Natural adsorbents, WHO, Adsorption isotherms, Batch, Column

(C) RASĀYAN. All rights reserved

\section{INTRODUCTION}

Water is known as a universal solvent because it dissolves almost all substance; that comes in its contact. the primary need of every human being is Safe drinking water. Pure water is inadequate and is not easily available at all. Water may be contaminated by natural sources or industrial effluents. One such contaminant is fluoride .

The natural presence of fluoride generally occurs through soil rock formation in the form of fluorapatite, geochemical deposits, natural water system and earth crust. ${ }^{1,2}$

Due to rapid urbanization and of modern industrial growth (anthropogenic source of fluoride) as well as the geochemical dissolution of fluoride-bearing minerals (natural source of fluoride), fluoride concentration is increasing in the environment including water resources. In additional fluoride found in various industrial activities, especially semiconductor, electroplating, glass, steel, ceramic and fertilizers industries. ${ }^{3}$ The high concentration in the drinking water leads to the destruction of the enamel of teeth and causes a number of conditions referred to collectively as fluorosis.According to WHO standards, in drinking water, the Fluoride should be within a range that slightly varies above and below $1 \mathrm{mg} / \mathrm{L} .{ }^{4} \mathrm{In}$ low water level, fluoride level is up to $1.5 \mathrm{mg} / \mathrm{L}$ and according to Bureau of Indian Standards, BIS (IS-10500) the desirable limit and permissible limit of Fluoride in drinking water is 1.0 and $1.5 \mathrm{mg} / \mathrm{L}$ respectively.The adsorption process is considered one of the most efficient methods for removal of fluoride from drinking water when compared to other techniques which are used for removal of fluoride based on initial cost, flexibility, and simplicity of design, ease of operation and maintenance. The

Rasayan J. Chem., 12(2), 455-463(2019)

http://dx.doi.org/10.31788/RJC.2019.1225106

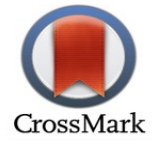


efficiency of this technique mainly depends on adsorbents. ${ }^{6}$ Adsorption depends upon solid adsorbent which is bond with weak intermolecular force by a solid surface.

Adsorption of fluoride on to solid absorbent usually occurs through three phases ${ }^{6}$ :

1. Diffusion or transport of fluoride ions to the external surface of the adsorbent from bulk solution across the boundary layer surrounding the adsorbent particle called external mass transfer;

2. Adsorption of fluoride ions on to particle surfaces.

3. The adsorbed fluoride ions probably exchange with the structural elements inside adsorbent particles depending on the chemistry of solids, or the adsorbed fluoride ions are transferred to the internal surfaces for porous materials(intraparticle diffusion). ${ }^{7}$

In the literature, defluoridation was studied using different biosorbents such as Cynodondactylon-based activated carbon ${ }^{8}$, thermally activated carbon prepared from neem (Azadirachtaindica) and kikar (Acacia arabica) leaves ${ }^{9}$, carbonaceous adsorbents such as wood charcoal or bone charcoal, coconut coir or animal bones ${ }^{10}$, metal ions impregnated activated charcoal ${ }^{11}$, activated charcoal prepared from wheat husk- and alum-treated fly ash ${ }^{12}$, bone charcoal, peels of Citrus document, Citrus medica, and Citrus aurantifolia fruits-based activated carbon $^{13}$, Moringa indicia bark, chitin/cellulose composite ${ }^{14}$, chitosan-coated silica $^{15}$, corn $\operatorname{cobs}^{16}$, rice husk ${ }^{17}$, tamarind seed and Moringa indicia-based activated carbon ${ }^{18,19}$ and bone meal. ${ }^{20}$

Thus, in the present work, a study of fluoride removal efficiency and adsorption capacity of some natural Adsorbents of Chhattisgarh region like Citron Peel,karanj,Paarijaat,Neem,Rice Husk and Tulsi was taken. However, these materials are available aplenty in this region.

\section{Fluoride Adsorption Experiments}

\section{EXPERIMENTAL}

A stock solution $(100 \mathrm{mg} / \mathrm{L}$ ) was prepared by dissolving $100 \mathrm{mg} \mathrm{NaF}$ (analytical grade) in $1 \mathrm{~L}$ of distilled water. Solutions for the experiment were prepared by dilution from the standard stock solution all studies were carried out with initial fluoride concentration solution in temperature controlled bath with a shaker. The adsorption isotherm at $\mathrm{pH} 6.90 \pm 0.10$ was studied by varying the initial fluoride concentration from 5 to $100 \mathrm{mg} / \mathrm{L}$. The effect of $\mathrm{pH}$ was investigated by adjusting the $\mathrm{pH}$ from 2 to 12 using $0.1 \mathrm{M} \mathrm{NaOH}$ and $\mathrm{HCl}$ solutions under an initial fluoride concentration of $10 \mathrm{mg} / \mathrm{L}$. A kinetic study at $\mathrm{pH} 6.90 \pm 0.10$ was carried out at different time intervals with an initial fluoride concentration of $10 \mathrm{mg} / \mathrm{L}$. Finally, the effects of a number of competing for ions $\left(\mathrm{Cl}^{-}, \mathrm{NO}_{3}{ }^{-}, \mathrm{CO}_{3}{ }^{2-}, \mathrm{SO}_{4}{ }^{2-}\right.$, and $\left.\mathrm{PO}_{4}{ }^{3-}\right)$ were observed using, 20$200 \mathrm{mg} / \mathrm{L}$ solutions at $\mathrm{pH} 6.90 \pm 0.10$ over 1 hour.

\section{Materials}

'Pyrex' quality Corning glassware and analytical reagent grade(AR) chemicals were used. The glassware was soaked in a $5.0 \mathrm{mg} /$ Lof Fluoride solution to minimize the possibility of absorption of fluoride for overnight. The glassware was washed off with nitric acid $\left(\mathrm{HNO}_{3}\right)$ and distilled water before use.First, a stock solution of $100 \mathrm{mg} \mathrm{F} / \mathrm{L}$ was prepared by dissolving an appropriate amount of sodium fluoride $(\mathrm{NaF})$ in distilled water and desired concentrations of working solutions were then prepared from stock solution. Sulphuric acid $(0.1 \mathrm{~N})$ and sodium hydroxide $(0.1 \mathrm{~N})$ were used for adjusting the $\mathrm{pH}$ values either too acidic or alkaline conditions.

Naturally occurring and abundantly available low-cost materials like Citron peel,karanj,Paarijaat,Neem,Rice Husk and Tulsi was obtained from the local market and campus area. These natural adsorbents are powdered in a local mill and were sieved through IS sieves of $150 \mu \mathrm{m}$ and $300 \mu \mathrm{m}$ size and the material passing through $150 \mu \mathrm{m}$ and retained on $300 \mu \mathrm{m}$ which has a geometric mean size $(\mathrm{Gm})$ of $212 \mu \mathrm{m}$ was used in all experiments. For the convenience, we abbreviated the adsorbents as BA-1, BA-2, BA-3, BA-4 BA-5, and BA-6.

\section{Methodology}

Batch sorption studies were conducted towards contact time, sorbent doses ,pH etc.

\section{Characterization of Adsorbents}

FT-IR spectrum is essential to identify the surface functional group. The broadband at $3701.40 \mathrm{~cm}-1 \mathrm{OH}$ stretching intermolecular hydrogen bonding of polymeric compound. The weak peak at $1715 \mathrm{~cm}-1$ in a 
spectrum to stretching $\mathrm{C}=\mathrm{O}$ in a carboxylic acid group corresponding to trace another acid for spectrum, the bands $1424 \mathrm{~cm}-1$ and $1326 \mathrm{~cm}-1$ with nearly equal intensity to $-\mathrm{CH}_{2}$ and $-\mathrm{OH}$ respectively. In following peak $681 \mathrm{~cm}-1$ stretched $\mathrm{C}-\mathrm{H}$ out plane bonding, $3431 \mathrm{~cm}-1$ stretched $\mathrm{O}-\mathrm{H}, 898 \mathrm{~cm}-1$ and 839 cm-1 stretched $\mathrm{C}-\mathrm{H}$ out of plane deformation.Abundant floristic fiber, protein and some functional groups such as carboxyl, hydroxy and amidogen, etc are the content of rice husk which makes adsorption processes possible. $^{21} 1034$ and $1257 \mathrm{~cm}-1$ are values for primary $\mathrm{C}-\mathrm{O}, 1321 \& 1386$ are for O-C secondary or tertiary, O-C 1618 is for conjugated carbonyl $\mathrm{C}=\mathrm{C}-\mathrm{C}=\mathrm{O}, 2854$ is for R-CHO's, C-H 2925 is for alkane's C-H 3430 is for carboxylic group's $\mathrm{O}-\mathrm{H}$ rest of the peaks are of $\mathrm{OH}$ or $\mathrm{CH}, 782$ is fingerprint and may be due to some ortho, meta or para substitution.

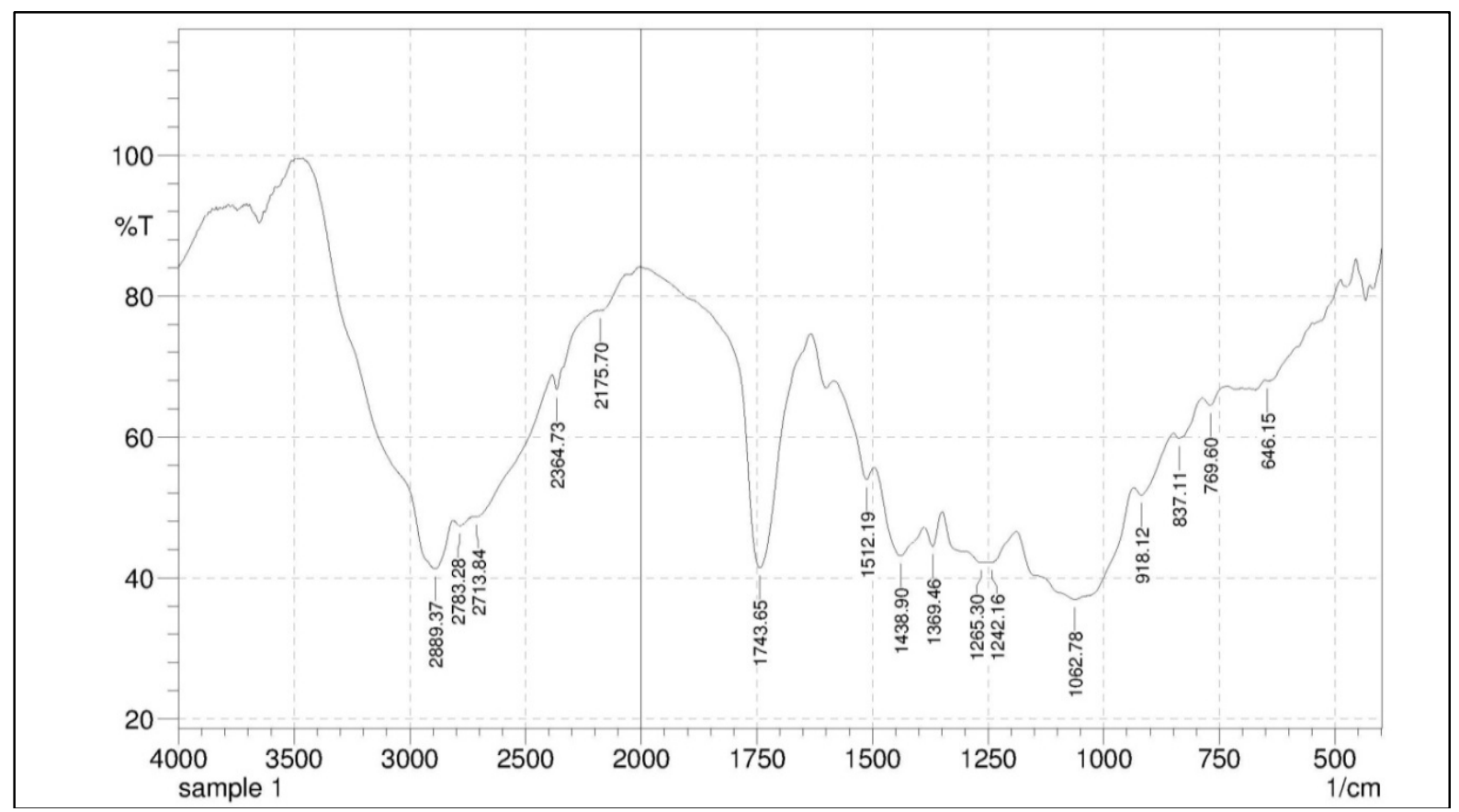

Fig.-1: FTIR - BA1

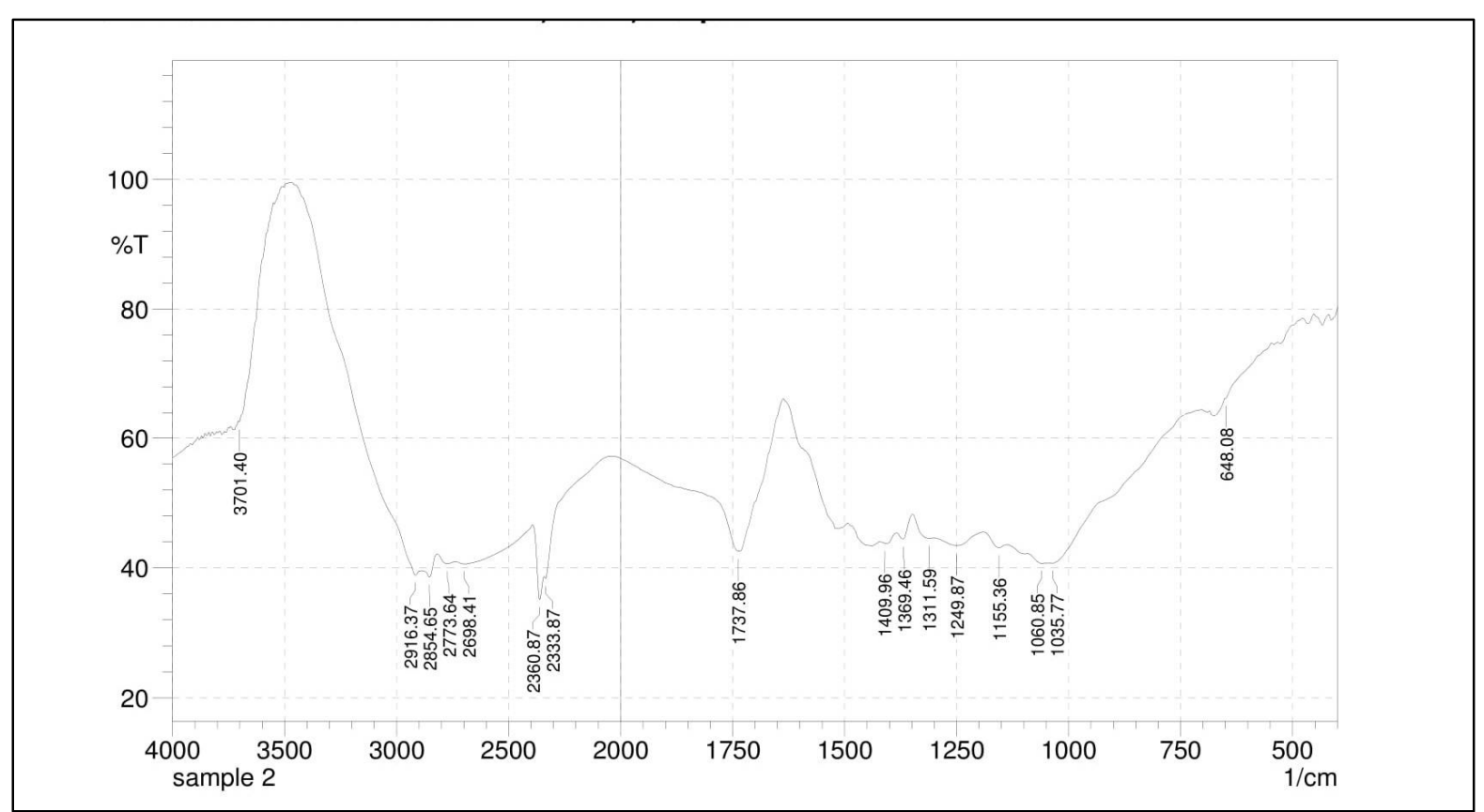

Fig.-2 : FTIR - BA2 
RASĀYAN J. Chem.

Vol. 12 | No. 2 |455 - 463| April - June | 2019

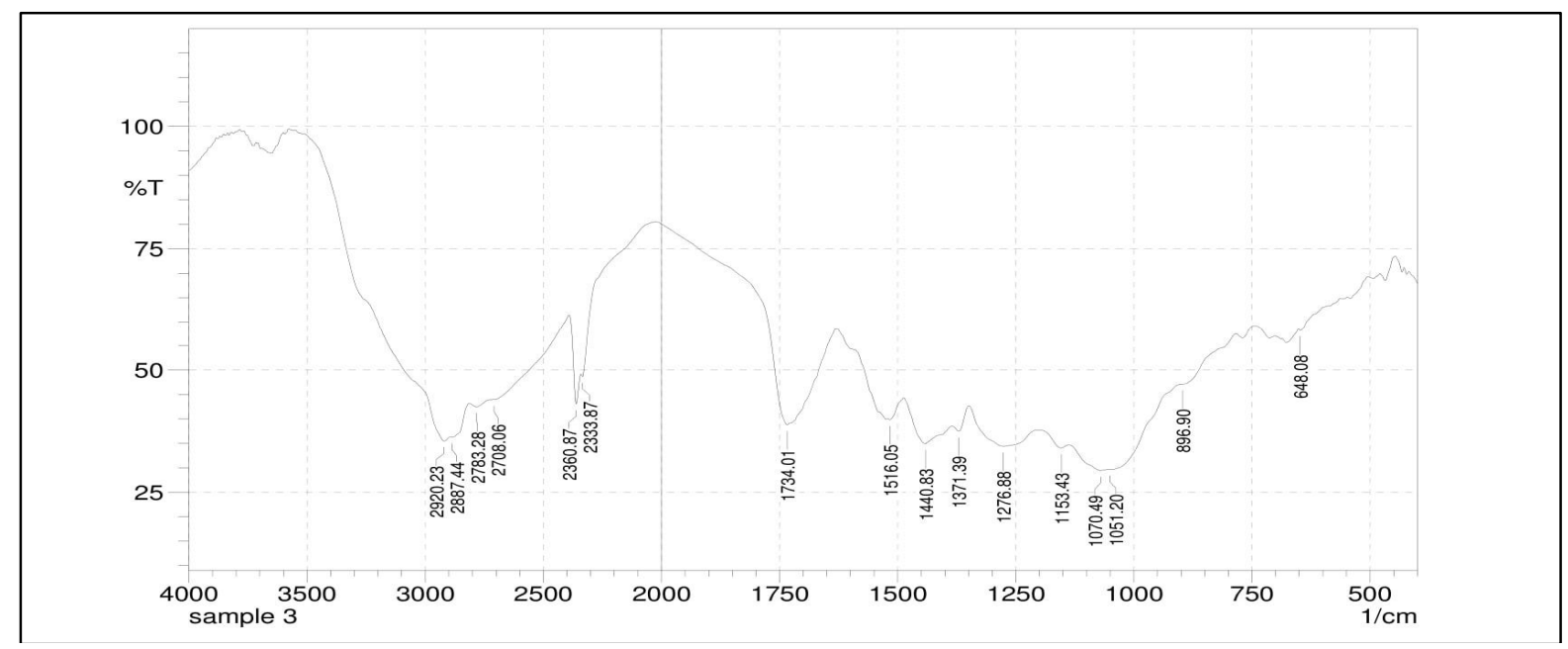

Fig.-3 : FTIR - BA3

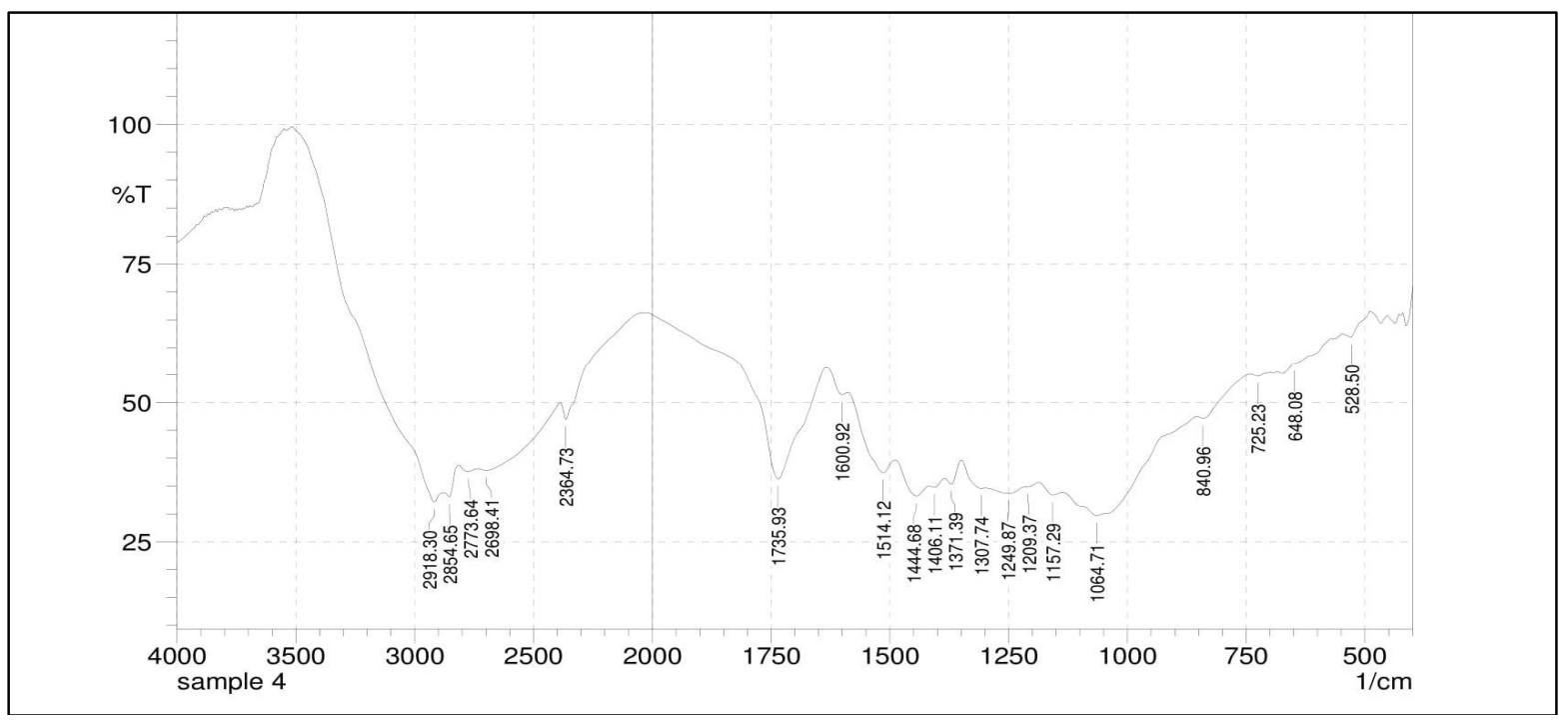

Fig.-4 : FTIR - BA4

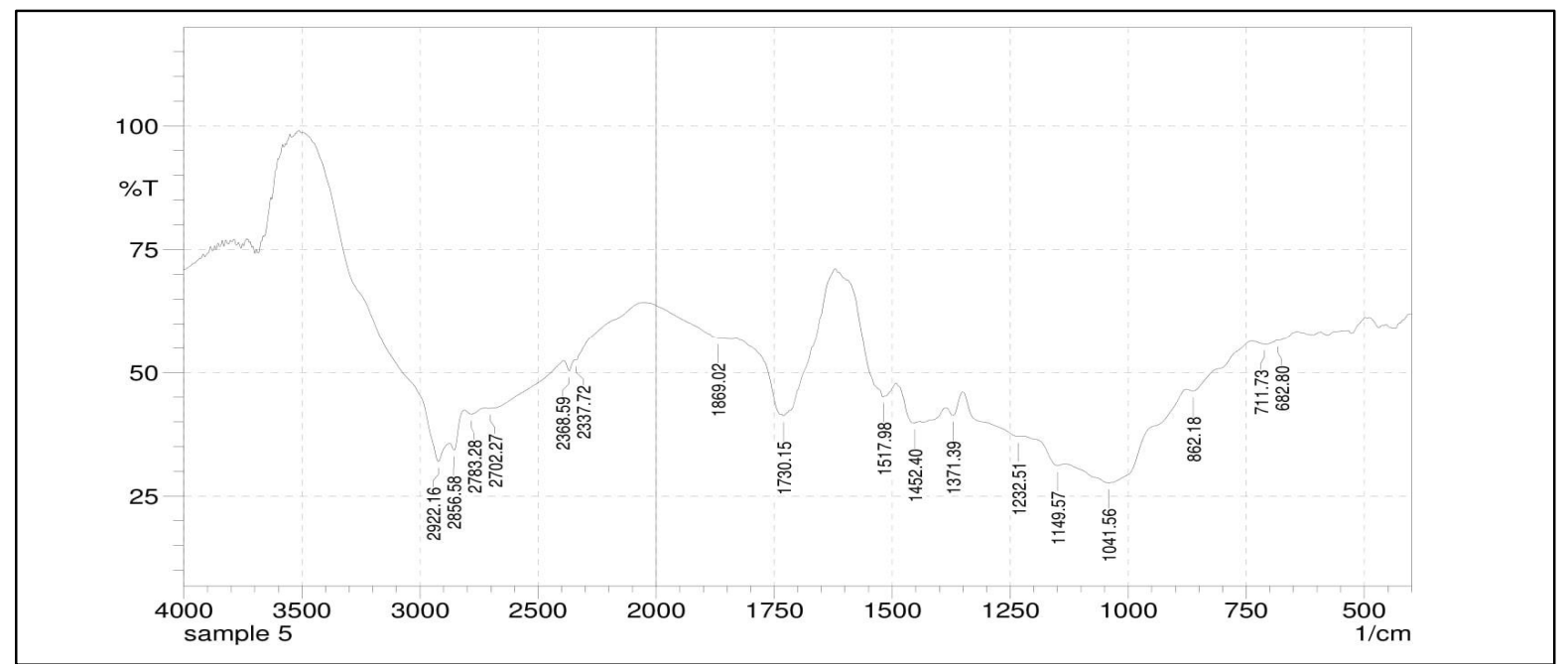

Fig.-5 : FTIR - BA5 


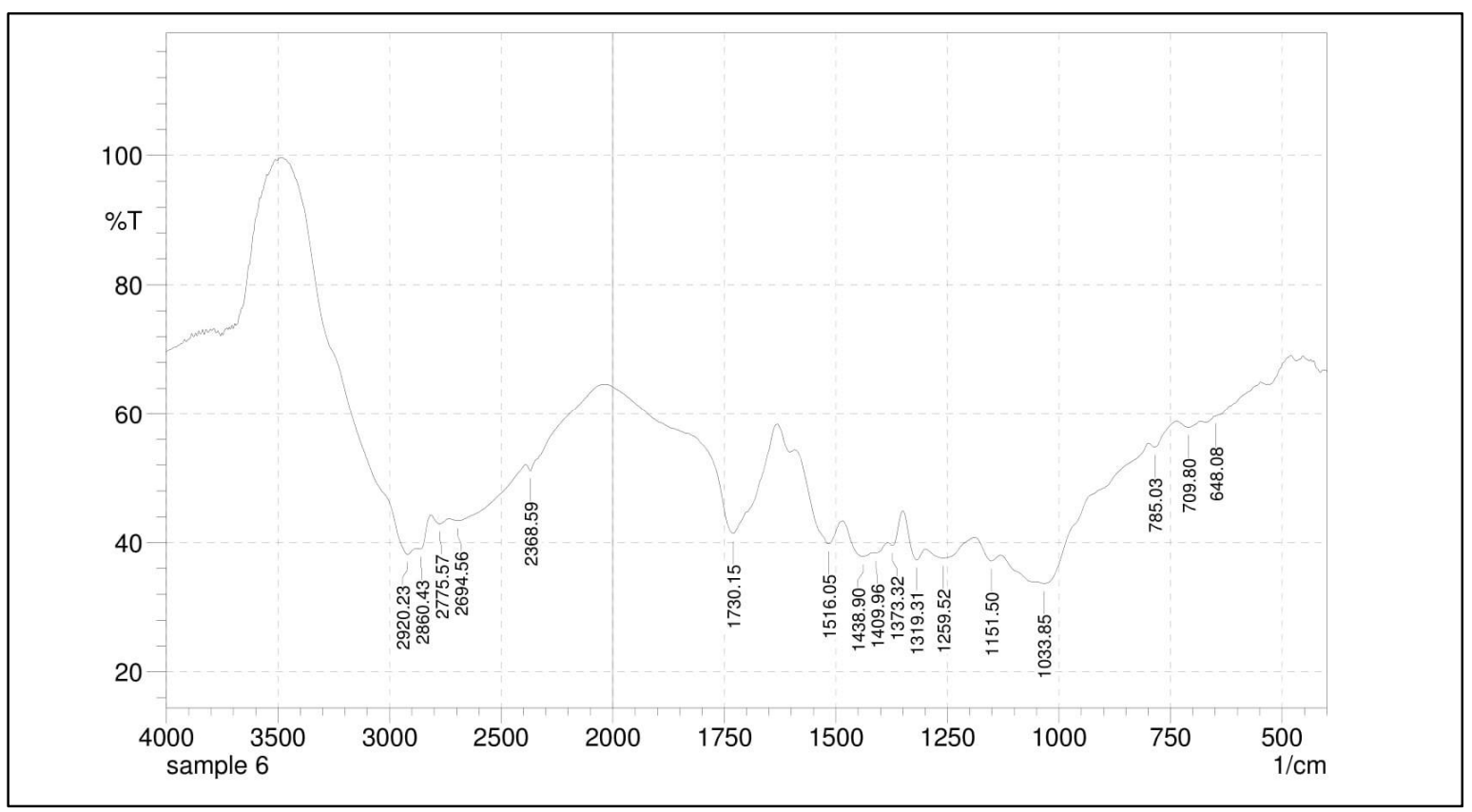

Fig.-6: FTIR - BA6

\section{RESULTS AND DISCUSSION}

Adsorption experiments were carried out for the determination of $\mathrm{pH}$, adsorbent dose variation, equilibrium time and kinetics, selection of an isotherm, effect of temperature and evaluation of thermodynamic parameters. The influence of $\mathrm{pH}(2.0-10.0)$, adsorbent dose (0.2-2.4 g /100 ml)and particle size $(200-350 \mu \mathrm{m})$,contact time $(20,40,60,80,120$ and $180 \mathrm{~min})$, initial fluoride concentration $(1.5,3.0,5.0,7.0,10.0$ and $20.0 \mathrm{mg} / \mathrm{L})$ were evaluated during the present study in a $250 \mathrm{ml}$ Erlenmeyer flasks and $100 \mathrm{ml}$ of fluoride solution of known concentration was added.

\section{Effect of Biosorbent Dose}

Results of equilibrium sorption experiments conducted with a test Fluoride solution of concentrations of $10.0 \mathrm{mg} / \mathrm{l}$ are presented in Fig.-7. The amount of Fluoride adsorbed increased with increase in dose and $89.5 \%, 98 \%, 87 \%, 82 \%, 92 \%$, and $98 \%$ removal was accomplished at a dosage of $5 \mathrm{~g} / \mathrm{L}$.

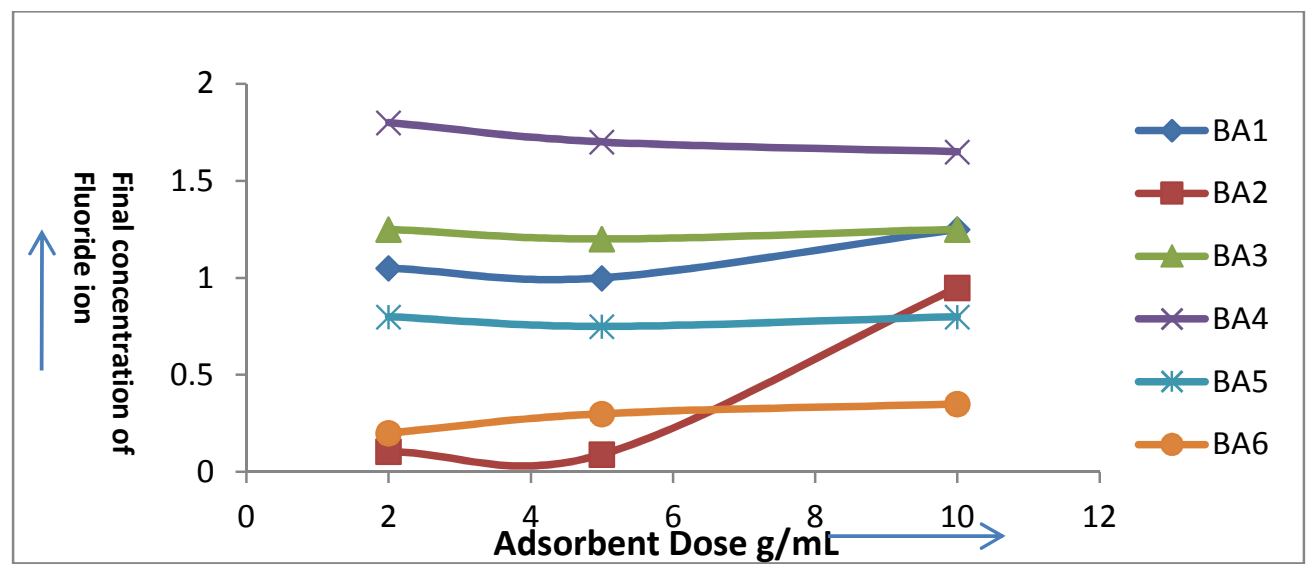

Fig.-7 Effect of Adsorbent Dose on \% Concentration of Fluoride Ion

The adsorption of fluoride was studied over a $\mathrm{pH}$ range as shown in Fig.-8. The fluoride removal increases with decreasing $\mathrm{pH}$ values and $\mathrm{pH}$ was increased from 2-10, the fluoride removal efficiency was increased in the acidic region 2-6 $\mathrm{pH}$ and gradually decreases in the alkaline region. The adsorption of 
other ions gets affected due to the strong affinity for $\mathrm{H}+$ and $\mathrm{OH}$-ions on adsorption sites. Because of $\mathrm{H}+$ ions concentrations at lower $\mathrm{pH}$, the negative charges on the adsorbent surface get neutralized. This is, in turn, reduces the diffusion of negatively charged fluoride ions and gives rise to the more active surface for adsorption. ${ }^{22}$

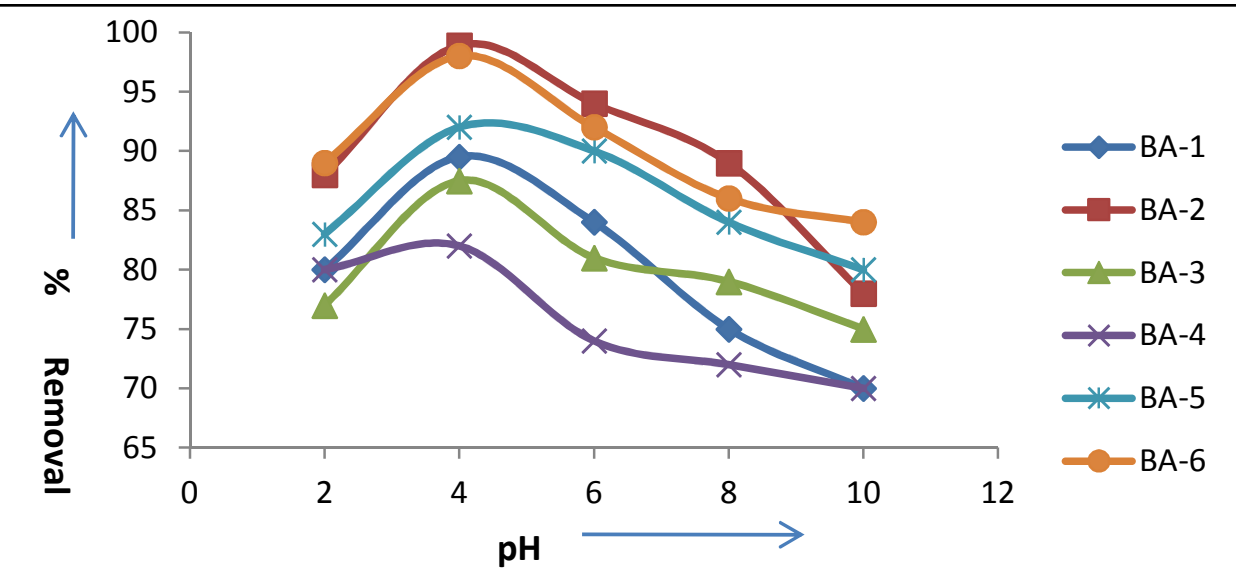

\section{Effect of Contact Time}

Fig.-8: Effect of $\mathrm{pH}$ on \% Removal of Fluoride Ion

The adsorption of the metal ion by adsorbent also depends on the interactions of functional groups between the solution and the surface of the adsorbent. Adsorptions can be assumed to be complete when equilibrium is achieved between the solute of a solution and the adsorbent. However, the specific time is needed to maintain the equilibrium interactions to ensure that the adsorption process is complete. ${ }^{23}$

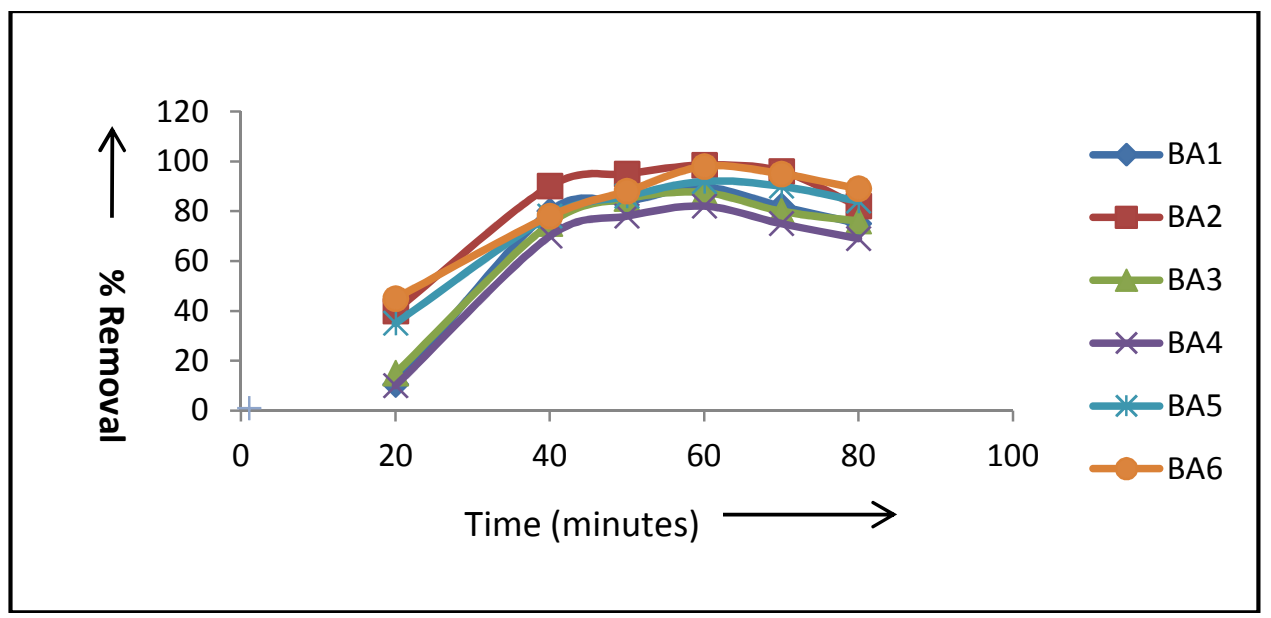

Fig.-9: Effect of Time on \% Removal of Fluoride Ion

The effect of contact time on removal on Fluoride using Bioadsorbents are presented graphically as percentage Fluoride removal at different contact times are shown in Fig.-9. It may be observed from the Figure that as contact time increases, percent removal also increases initially and reduces gradually with time and attains almost an equilibrium condition in nearly 60 minutes (1 hour) and remains more or less constant thereafter.

\section{Isotherm}

The mechanism of adsorption could be determined by evaluating the equilibrium data also known adsorption data obtained from the experiment. An equilibrium relationship between the amount of fluoride adsorbed on the surface of an adsorbent could be established through adsorption isotherms. In 
the present study, both Langmuir and Freundlich isotherm models have been used to examine the adsorption data. Langmuir isotherm was found to be the best fit compared to Freundlich isotherm.

\section{Langmuir Isotherm}

$(\mathrm{Ce} / \mathrm{Qe})=(\mathrm{Ce} / \mathrm{Qm})+(1 / \mathrm{Qmb})$

Where,

$\mathrm{Ce}-$ effluent fluoride concentration

$\mathrm{Qe}=\mathrm{X} / \mathrm{m}$

$\mathrm{b}$ - Langmuir constant

\section{Freundlich Isotherm}

$$
\begin{aligned}
& \text { InQe }=\text { In } \mathrm{k}+(1 / \mathrm{n}) \operatorname{InC} \\
& \text { Where, } \\
& \mathrm{k}-\text { Freundlich constant } \\
& \mathrm{n}-\text { order }
\end{aligned}
$$

\section{Langmuir Isotherm}

The basics assumption of Langmuir models is that the formation of monolayer take place on the surface of the adsorbent indicating that only one fluoride molecule could be adsorbed on one adsorption site and the inter-molecule force decrease with distance. It also assumes that the adsorbent surface is homogeneous in characters and possesses identically and energetically equivalent adsorption site. The Langmuir models are given by the following equation:

$$
(\mathrm{Ce} / \mathrm{Qe})=(\mathrm{Ce} / \mathrm{Qm})+(1 / \mathrm{Qmb})
$$

It was further observed that equilibrium behavior can be predicted by Langmuir adsorption isotherm. Experimental data fitted with relatively good correlation coefficient as 0.997. It showed that the Langmuir model can be accepted for this process. It is shown for various adsorbents from Fig.-10 to 15.

\section{CONCLUSION}

Different types of Bioadsorbents used in this study shows a better adsorption capacity of fluoride. The adsorption removal of fluoride increases with decreases $\mathrm{pH}$ value and the maximum fluoride removal occurred at the range $\mathrm{pH} 2-6$. The fluoride removal increases with increases temperature, contact time and adsorbent doses. It was further observed that equilibrium behavior can be predicted by Langmuir adsorption isotherm.

Langmuir Theorem- (BA-1)

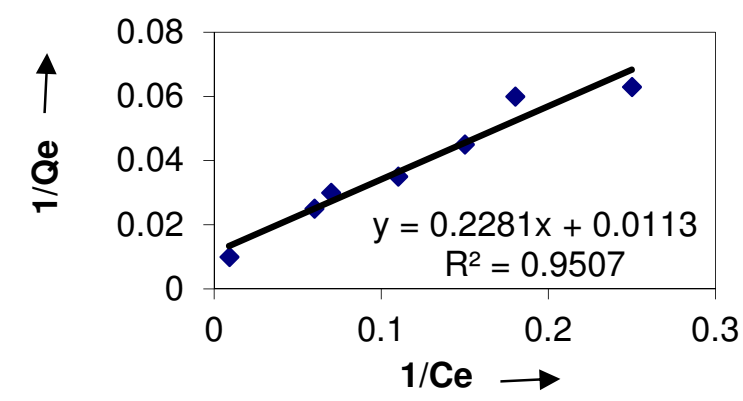

Fig.-10
Langmuir Theorem (BA-4)

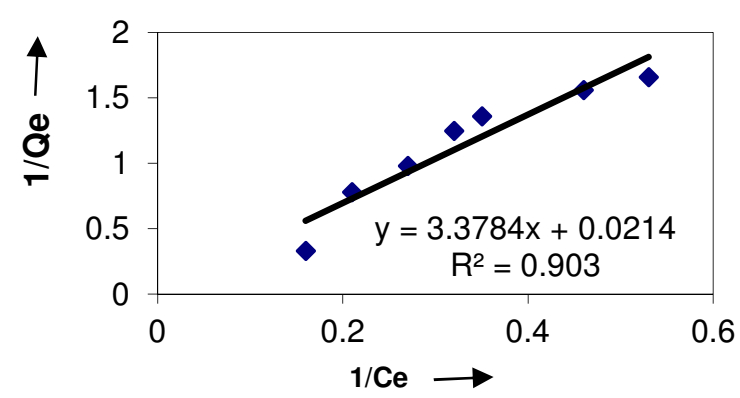

Fig.-11 


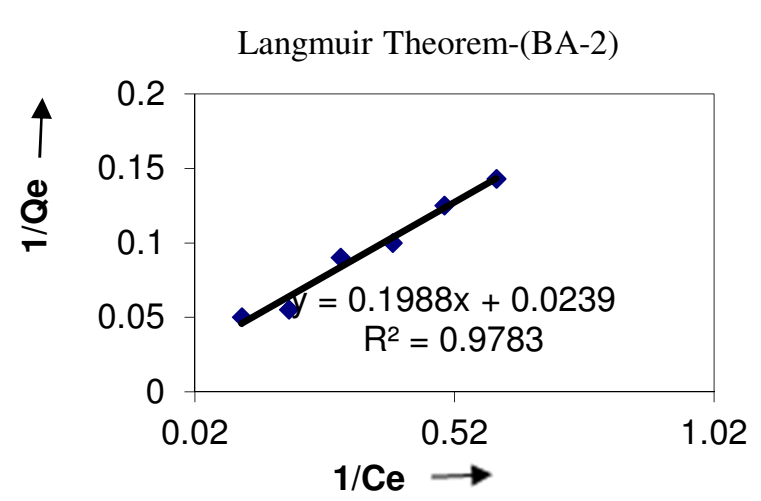

Fig.-12

Langmuir Theorem( BA-3)

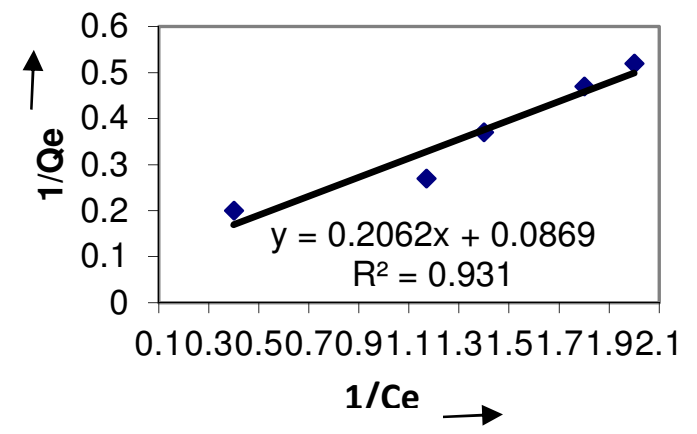

Fig.-13

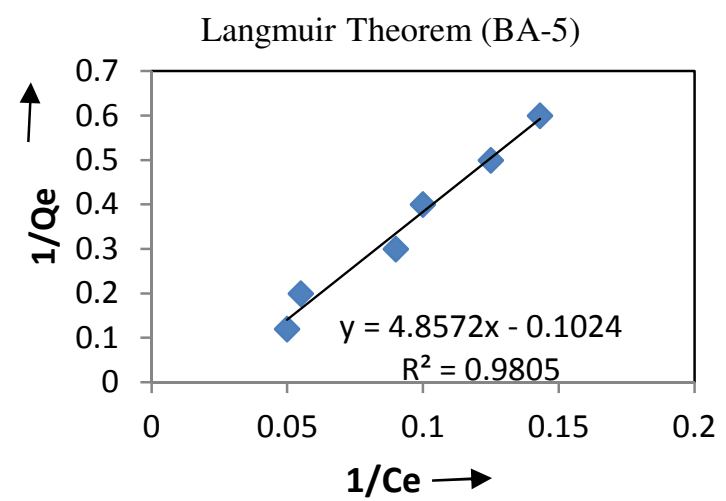

Fig.-13

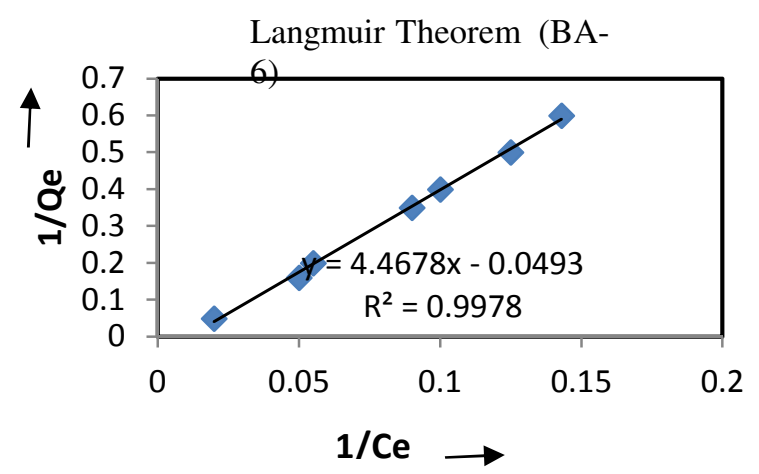

Fig.-14

\section{REFRENCES}

1. M. Bishnoi, S. Arora, Journal of Environ. Biol., 28, 2, 291(2007).

2. K. Shailaja, M. E. C. Johnson, Journal of . Environmental and Biology, 28, 2, 331(2007).

3. A. Toyoda, A. Taira, IEEE Trans, Semiconductor, Manufacture, 13, 305(2000).

4. Meenakshi, R.C., Fluoride in Drinking Water and its Removal, Center for Rural Development and Technology, IIT, Delhi, (2006).

5. BIS 10500, Indian Standard Drinking Water Specification, Bureau of Indi Standards, New Delhi, (1991).

6. Stanic Mirna Habuda, Ravancic Maja Ergovic, Flanagan Andrew, Materials, 7 , 6317(2014), DOI:10.3390/ma7096317.

7. Stoica Ligia, Constantin Carolina, Calin Cristina, U.P.B. Sci. Bull., Series B, 74(4), 87(2012).

8. G. Alagumuthu, V. Veeraputhiran ,R. Venkataraman , Hem. Ind., 65(1),23(2011).

9. S. Kumar, A. Gupta, J. P. Yadav, Journal of Environment and Biology, 29(2), 227(2008).

10. A. Sivasamy, K. P. Singh, D. Mohan , M. Maruthamuthu, Journal of Chemical Technology and Biotechnology, 176,717(2001).

11. C. Janardhana, G. Nageswara Rao ,R. Sai Satish ,V. Sai Lakshman, Indian Journal of Chemical Technology, 13, 414(2006).

12. R. P. Singh ,Y. Singh , D. Swaroop , Bull. Environ. Contam. Toxicology, 65, 120(2000), DOI:10.1007/500/280000/03.

13. C.H. Chakrapani , Suresh Babu , K. N. K. Vani , K. Somasekhara Rao, E-J Chem.,7, 4(2010).

14. G. Jayapriya, Ramya .R., XR. Rathinam, Sudha P.N., Arch. Appl. Sci. Res., 3(3), 415(2011).

15. Y. Vijaya ,A. Krishnaiah, Journal of Chemistry, 6(3),713(2009), DOI:10.1155/2009/748153.

16. S. P. Hemant, B. P. Jignesh, P. Sudhakar, V. J. Koshy, Journal of Environmental Science and Engineering, 48(2),135(2006) .

17. S. D. Waheed, S.J. Attar, M.D. Waghmare, Natural Environment and Pollution Technology,8(2), 217(2009). 
RASĀYAN J. Chem.

Vol. 12 | No. 2 |455 - 463| April - June | 2019

18. M. Murugan ,E. Subramanian, Journal of Water and Health., 4(4), 453(2007), DOI:10.216/wh.2006.014.

19. G. Karthikeyan ,S. S. Ilango, Journal of Environmental Health Science Eng., 4(1), 21(2007)

20. S. Gao, J. Cui , Z. Wei, Journal of Fluor. Chem., 130, 1035(2009).

21. H. Runping ,W. Yuanfeng, Y. Weihong ,Z. Weihua ,S. Jie, and L. Hongmin, Water Supply, 2(1), 311.

22. Deepankar Dev Pandey, Apoorva Tripathi, Tej Pratap Singh , International Journal of Science, Engineering and Technology, 4, 69(2016).

[RJC-5106/2018] 